\title{
Stability in Population of Phytophthora infestans Attacking Tomato in Ecuador Demonstrated by Cellulose Acetate Assessment of Glucose-6-Phosphate Isomerase
}

\author{
Lynn J. Erselius, Miguel E. Vega-Sánchez, and Gregory A. Forbes, International Potato Center (CIP), P.O. Box \\ 17-21-1977, Quito, Ecuador
}

\begin{abstract}
Erselius, L. J., Vega-Sánchez, M. E., and Forbes, G. A. 2000. Stability in population of Phytophthora infestans attacking tomato in Ecuador demonstrated by cellulose acetate assessment of glucose-6-phosphate isomerase. Plant Dis. 84:325-327.

Cellulose acetate electrophoresis was used to examine glucose-6-phosphate (Gpi) isomerase banding patterns of the population of Phytophthora infestans attacking tomato in Ecuador. All but two of 160 sporulating lesions from tomato leaflets collected from 25 tomato fields between January 1998 and March 1999 produced the 86/100 Gpi isozyme electromorph. This isozyme type is characteristic of the US-1 clonal lineage, indicating that no change in the population of $P$. infestans attacking tomato in Ecuador has occurred since a more exhaustive study was done using isolates collected between 1993 and 1995. The two lesions that produced a different Gpi electromorph in the current study came from a field that was located approximately $80 \mathrm{~m}$ from a potato field that had been severely affected by late blight. These two isolates produced a single large band for Gpi with a relative migration distance of 100. This electromorph is characteristic of the clonal lineage EC-1, which was shown previously to be the predominant clonal lineage attacking potato in Ecuador. Therefore, we assume that the two tomato lesions with the EC-1 phenotype were caused by inoculum originating from the potato field. During the current study, 34 infected potato leaflets were collected from five potato fields found in close proximity to blighted tomato fields. All of the potato leaflets produced banding patterns characteristic of EC1. Our data are consistent with earlier studies indicating that, in Ecuador, tomato and potato are attacked by separate populations of $P$. infestans, which belong to two different clonal lineages.
\end{abstract}

The population of Phytophthora infestans (Mont.) de Bary in Ecuador is made up of at least two host-specific clonal lineages (15). Recent studies demonstrated that almost all isolates taken from potato belong to the clonal lineage EC-1 (4) and almost all isolates taken from tomatoes belong to the clonal lineage US-1 (15). EC-1 has some characteristics found in European populations of the pathogen (4). US- 1 is found globally and was the predominant clonal lineage outside North America until the 1980s (7). Both EC-1 and US-1 are A1 mating type. A Phytophthora sp. population with A2 mating type that attacks the wild hosts Solanum brevifolium and S. tetrapetalum in Ecuador was tentatively described as the EC-2 clonal lineage of $P$. infestans (14). However, its species designation is still uncertain and there is no evidence for sexual recombination between this A2 population and the A1 lineages in Ecuador (14).

Isolates taken from tomato in Ecuador in the past were US-1 (15), with the 86/100 banding pattern for glucose-6-phosphate

Corresponding author: G. A. Forbes
E-mail: forbes@cip.org.ec

Accepted for publication 20 November 1999.

Publication no. D-2000-0124-03R

(C) 2000 The American Phytopathological Society
(Gpi) isomerase. Neither EC-1 nor EC-2 has the 86/100 pattern for Gpi. Therefore, should a genotype from either of these lineages evolve aggressiveness on tomato and replace US- 1 on that host, the change would be readily detectable by assessment of Gpi alone. The loss of the 86 allele can also occur within the US-1 lineage, thus resulting in a 100/100 homozygote (7) but, in this case, the lineage can be identified with other markers, especially restriction fragment length polymorphisms (RFLPs; 7).

The tomato population in Ecuador could also potentially be displaced by a clonal lineage or sexual population introduced from another part of the world. Long-distance transport of this pathogen occurs primarily on potato tubers (6), and most tubers introduced into Ecuador or neighboring countries (for seed or human consumption) come from the United States, Canada, or Europe. The 86/100 pattern of Gpi is extremely rare at this time in the United States, Canada (9), and Europe $(3,5,6,12,16,17)$. Therefore, if new lineages or sexual populations that attack tomato are introduced into Ecuador from these areas, it is highly probable they would also be easily detectable by assessment of Gpi.

Electrophoresis using cellulose acetate membranes is a simple, fast technique for distinguishing the $86 / 100 \mathrm{Gpi}$ banding pattern from other $G p i$ banding patterns (8). With this technique, assessments can be made directly from diseased tissue, without the need to isolate the samples in pure culture (8). This greatly reduces the time needed to process individual samples.

Cellulose acetate has been used to identify allozyme phenotypes of isolates and characterize populations of $P$. infestans in the United States $(8,9)$. In the current study, we use this method to test the hypothesis that no change has occurred within the population of $P$. infestans attacking tomato in Ecuador. We also suggest areas of the world where a similar approach may provide a rapid and inexpensive technique for monitoring change in the populations of $P$. infestans attacking tomato or potato.

\section{MATERIALS AND METHODS}

Infected leaflets were collected from tomato fields in central and northern Ecuador between January 1998 and March 1999 (Table 1). Leaflets were sampled at random on a single transect across each field. When possible, at least five leaflets were taken from each field, but only one lesion was taken from any single plant. Blighted potatoes in adjacent fields were also sampled.

Some lesions were tested immediately after returning from the field. Others were rinsed either in $0.5 \%$ hypochlorite solution or distilled water, then patted dry with paper towels and incubated overnight in humid chambers at $15^{\circ} \mathrm{C}$ to encourage sporulation. Some diseased leaflets in poor condition from the first sampling in Pallatanga (Table 1) were used to inoculate leaflets of the tomato cultivar FMX-93, which has no known $\mathrm{Ph}$ genes for racespecific resistance. First, a drop of water (approximately $50 \mu \mathrm{l}$ ) was placed on the adaxial side of a healthy FMX-93 leaflet. Then, a small piece of diseased tissue from a collected leaflet was inserted into this drop. Inoculated leaflets were incubated in the lids of inverted petri dishes at $15^{\circ} \mathrm{C}$ with $14 \mathrm{~h} /$ day of fluorescent light as described previously (15). Gpi was assessed using the new lesions after 5 or 6 days of incubation.

Gpi was extracted from diseased tissue as described previously (8), but with slight modifications. Small pieces of sporulating, infected tissue (approximately $1 \mathrm{~cm}^{2}$ ) were cut from the edge of lesions and placed into 1.5-ml Eppendorf tubes with $100 \mu \mathrm{l}$ of distilled water. The tissue pieces were then ground manually with a polyurethane tip, which closely fit the form of the Eppendorf 
tube. The extracts were then centrifuged for about $30 \mathrm{~s}$ at $14,000 \mathrm{rpm}(16,000 \times g)$, put on ice, and used immediately for electrophoresis as described previously (8). A total of 12 samples were run on a single cellulose acetate gel, and sometimes two gels were run at the same time. Known controls for the Gpi banding patterns $86 / 100$ and $90 / 100$ were included on each gel. These samples were either extracted from infected leaf tissue as described above or from lyophilized tissue as described previously (8).

\section{RESULTS}

Late blight was found on tomatoes in most collection trips. Late blight was not found, however, in a large tomato-producing region in northern Ecuador known as El Chota, or in several greenhouses in the valley of Los Chillos near the capital city of Quito. Furthermore, late blight was not always severe at the other sites, as, for example, in Guayabamba in March 1999, which sometimes limited the number of samples that could be collected (Table 1).

In general, the procedure for measuring $G p i$ from field-infected lesions worked very well. Gpi banding patterns were easy to distinguish and fewer than 10 lesions had to be repeated. Patterns from infected tissue were at times slightly more smeared than those coming from lyophilized tissue of a pure culture of $P$. infestans, but this

Table 1. Glucose-6-phosphate isomerase banding patterns produced on cellulose acetate by extracts from blighted tomato and potato leaflets that were collected in fields at different locations in Ecuador

\begin{tabular}{|c|c|c|c|c|c|}
\hline \multirow[b]{2}{*}{ Host and date } & \multirow[b]{2}{*}{ Nearest town $^{a}$} & \multirow[b]{2}{*}{ No. of fields } & \multirow[b]{2}{*}{ No. of samples } & \multicolumn{2}{|c|}{ Banding pattern } \\
\hline & & & & $86 / 100$ & Single band ${ }^{\mathrm{b}}$ \\
\hline \multicolumn{6}{|l|}{ Potato } \\
\hline January 1998 & Pallatanga & 1 & 1 & 0 & 1 \\
\hline January 1998 & Pallatanga & 1 & 18 & 0 & 18 \\
\hline June 1998 & Guayabamba & 1 & 10 & 0 & 10 \\
\hline March 1999 & Guayabamba & 2 & 3 & 0 & 3 \\
\hline \multicolumn{6}{|l|}{ Tomato } \\
\hline January 1998 & Pallatanga & 2 & 12 & 10 & 2 \\
\hline January 1998 & Guamanpata & 2 & 12 & 12 & 0 \\
\hline May 1998 & Alchichipa & 2 & 6 & 6 & 0 \\
\hline May 1998 & Alobuela & 1 & 2 & 2 & 0 \\
\hline June 1998 & Tabacundo & 1 & 9 & 9 & 0 \\
\hline June 1998 & Guayabamba & 4 & 33 & 33 & 0 \\
\hline June 1998 & Guayabamba & 2 & 22 & 22 & 0 \\
\hline December 1998 & Pallatanga & 7 & 36 & 36 & 0 \\
\hline March 1999 & Puellaro & 1 & 10 & 10 & 0 \\
\hline March 1999 & Alchichipi & 1 & 16 & 16 & 0 \\
\hline March 1999 & Guayabamba & 2 & 2 & 2 & 0 \\
\hline Total & $\ldots$ & $25 / 5^{\mathrm{c}}$ & 192 & 158 & 34 \\
\hline
\end{tabular}

a Nearest town to sampling location. More precise information on the location of samples can be supplied by the corresponding author.

b These lesions produced a single band on cellulose acetate. EC-1 isolates from potato characteristically produce a $90 / 100$ banding pattern starch gels, but only produce a single band (identical to $100 / 100)$ on cellulose acetate.

c Total number of fields: 25 tomato and 5 potato.

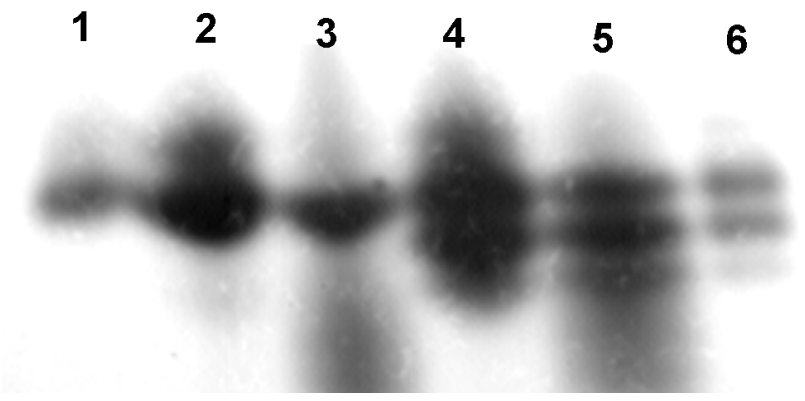

Fig. 1. Glucose-6-phosphate isomerase banding patterns of extracts of Phytophthora infestans produced on cellulose acetate. Lane 1, lyophilized tissue of an isolate with a known 100/100 phenotype from the Cornell University collection of $P$. infestans; lane 2, lyophilized tissue of an isolate collected previously from potato in Ecuador and identified as 90/100 phenotype with starch gel electrophoresis; lane 3, infected tissue from potato leaflet-pathogen assumed to have 90/100 phenotype; lane 4, lyophilized tissue of an isolate collected previously from tomato in Ecuador and identified as 86/100 phenotype with starch gel electrophoresis; lane 5, infected tissue from tomato leaflet-pathogen assumed to have 86/100 phenotype; and lane 6, lyophilized tissue of an isolate with a known 86/100 phenotype from the Cornell University collection of $P$. infestans. The 90/100 pattern can be distinguished from 100/100 on starch gels but not on cellulose acetate.

did not interfere with identification of the $86 / 100$ pattern or the single band of the lesions on potato leaflets (Fig. 1). The presence of host tissue did not affect the banding pattern.

Of the 192 lesions tested, 160 came from tomato and 32 came from potato. All tomato lesions except two produced three distinct bands, identical to those of the $86 / 100$ control isolate, and all potato isolates produced a single band at the migration distance of the 100 allele, as did the 90/100 control isolate (Fig. 1), which has the same phenotype as EC-1. Two isolates from tomato collected in Pallatanga in January 1998 (Table 1) produced a single band, like isolates from potato.

\section{DISCUSSION}

Current sampling indicated that the population of $P$. infestans attacking tomato in Ecuador is most likely US-1 and no change was detected since a more exhaustive study was done using isolates collected between 1993 and 1995 (15). This hypothesis is supported by several observations. The $86 / 100$ banding pattern for Gpi does not occur in the local clonal lineages EC-1 (4) or EC-2 (14), nor is it common in populations in the United States, Canada (9), and Europe $(3,5,6,12,16,17)$. It is thus unlikely that a new tomatoaggressive genotype from a local or foreign source would have the $86 / 100$ banding pattern for Gpi. Furthermore, if a new genotype of $P$. infestans with $86 / 100$ for Gpi had been introduced, it would probably have been brought in on potato tubers (tomato plantlets and fruits are not imported) and, as such, would be a potatoaggressive population. At this time, we have no evidence of a potato-aggressive population in Ecuador with the $86 / 100$ banding pattern. For these reasons, we conclude that the population of $P$. infestans attacking tomato in Ecuador has been stable for at least the last 5 years. The available evidence suggests that US- 1 was the predominant clonal lineage on potato in the Andes during the 1980s $(4,7)$. It is reasonable to assume, therefore, that it was also the predominant clonal lineage attacking tomato at that time.

Our study has implications for tomato and potato disease management in Ecuador. There is evidence from studies in North America that genotypes of $P$. in festans exist that are highly aggressive on both hosts (13). If a population of the pathogen that attacked both hosts equally were introduced into Ecuador, it would make disease management more difficult. Potatoes are generally grown at higher elevations than are tomatoes in Ecuador, but the production zones often overlap. There also is a tendency at this time to grow tomatoes at higher elevations in greenhouses. These tomatoes are often found directly within potato production zones. 
The data also have clear implications for fungicide management. EC-1, the clonal lineage attacking potato, has a high frequency of genotypes resistant to metalaxyl (4). This is undoubtedly one of the reasons that metalaxyl is not used frequently for control of late blight on potato in Ecuador (2). We are not aware of the usage patterns of metalaxyl for tomato, but studies conducted a few years ago indicated that high levels of resistance to this fungicide are not common in the US-1 clonal lineage attacking tomato in Ecuador (15). Although US-1 can become resistant to metalaxyl $(10,11)$, fungicide-management strategies could reduce selection for resistant genotypes. Population migration was also associated with increased resistance to metalaxyl (6) and the potential for introduction of populations already resistant to metalaxyl exists for Ecuadorian tomato producers. For these reasons, monitoring of the tomato pathogen populations should continue. Until the pathogen population becomes more complex, cellulose acetate appears to be a relatively fast and inexpensive way of screening large numbers of lesions. More informative markers may be used on sub-samples, to confirm the results of cellulose acetate.

The data are consistent with an earlier study (15) showing that populations of $P$. infestans attacking potato and tomato in Ecuador are quantitatively host specific. In that study, cross inoculation on detached leaflets showed that each clonal lineage is able to attack both hosts, but lesion size is greater on the original host. None of the isolates we examined from potato in this study had the $86 / 100$ banding pattern, while almost all isolates from tomato did. Therefore, we conclude that potato and tomato are still attacked by host-specific populations of $P$. infestans in Ecuador. These host-specific populations can, on rare occasions, be isolated from their alternative hosts; two of our isolates from tomato were apparently from the potato population. Nonetheless, genotypes of $P$. infestans in Ecuador do not appear to pose a real epidemiological threat to their alternative hosts (15).

There appears to be no evidence that the two tomato lesions apparently caused by EC-1 represent a subpopulation that had evolved pathogenic aggressiveness on tomato. Or, if they do, this genotype was apparently not competitive with US-1 for other reasons. All lesions collected 1 year later from tomato plants in the same region produced the $86 / 100$ banding pattern, and are assumed to be US-1. Therefore, EC-1 does not appear to have established itself on tomato in the region.

Cellulose acetate electrophoresis provides a convenient and rapid method for surveying the population of $P$. infestans directly from lesions when it is known that the population is clonal and has a unique or rare Gpi or Pep banding pattern (9). This simple and rapid monitoring procedure could be very useful in regions or countries where the US-1 lineage is still the predominant population on potato (and presumably tomato), such as in sub-Saharan Africa, Chile, and Australia (unpublished data), or only on tomato, such as in Brazil (1). We believe that the introduction of foreign genotypes into these areas would most probably result in changes in the Gpi pattern that could be easily detected with cellulose acetate. The arguments we gave which support this hypothesis for Ecuador would also apply to other countries where US-1 is still predominant.

\section{LITERATURE CITED}

1. Brommonschenkel, S. H. 1988. Pathogenicity, compatibility, cytogenetics and isoenzyme patterns of Brazilian isolates of Phytophthora infestans (Mont.) de Bary. MS Thesis, Universidade Federal de Viçosa, Viçosa, Brazil.

2. Crissman, C. C., Espinosa, P., Ducrot, C. E. H., Cole, D. C., and Carpio, F. 1998. The case study site: physical, health and potato farming systems in Carchi province. Pages 85-120 in: Economic, Environmental, and Health Tradeoffs in Agriculture: Pesticides and the Sustainability of Andean Potato Production. C. C. Crissman, J. M. Antle, and S. M. Capalbo, eds. Kluwer Academic Publishers, Dordrecht, The Netherlands.

3. Daggett, S. S., Götz, E., and Therrien, C. D. 1993. Phenotypic changes in populations of Phytophthora infestans from Eastern Germany. Phytopathology 83:319-323.

4. Forbes, G. A., Escobar, X. C., Ayala, C. C., Revelo, J., Ordoñez, M. E., Fry, B. A., Doucett, K., and Fry, W. E. 1997. Population genetic structure of Phytophthora infestans in Ecuador. Phytopathology 87:375-380.

5. Fry, W. E., Drenth, A., Spielman, L. J., Mantel, B. C., Davidse, L. C., and Goodwin, S. B. 1991. Population genetic structure of Phytophthora infestans in the Netherlands.
Phytopathology 81:1330-1336.

6. Fry, W. E., Goodwin, S. B., Dyer, A. T., Matuszak, J. M., Drenth, A., Tooley, P. W., Sujkowski, L. S., Koh, Y. J., Cohen, B. A., Spielman, L. J., Deahl, K. L., Inglis, D. A., and Sandlan, K. P. 1993. Historical and recent migrations of Phytophthora infestans: Chronology, pathways, and implications. Plant Dis. 77:653-661.

7. Goodwin, S. B., Cohen, B. A., and Fry, W. E. 1994. Panglobal distribution of a single clonal lineage of the Irish potato famine fungus. Proc. Natl. Acad. Sci. USA 91:11591-11595.

8. Goodwin, S. B., Schneider, R. E., and Fry, W. E. 1995. Use of cellulose-acetate electrophoresis for rapid identification of allozyme genotypes of Phytophthora infestans. Plant Dis. 79:1181-1185.

9. Goodwin, S. B., Smart, C. D., Sandrock, R W., Deahl, K. L., Punja, Z. K., and Fry, W. E. 1998. Genetic change within populations of Phytophthora infestans in the United States and Canada during 1994 to 1996: Role of migration and recombination. Phytopathology 88:939-949.

10. Goodwin, S. B., Sujkowski, L. S., and Fry, W. E. 1996. Widespread distribution and probable origin of metalaxyl resistance in clonal genotypes of Phytophthora infestans in the United States and western Canada. Phytopathology 86:793-800.

11. Koh, Y. J., Goodwin, S. B., Dyer, A. T., Cohen, B. A., Ogoshi, A., Sato, N., and Fry, W. E. 1994. Migrations and displacements of Phytophthora infestans populations in east Asian countries. Phytopathology 84:922-927.

12. Lebreton, L., and Andrivon, D. 1998. French isolates of Phytophthora infestans from potato and tomato differ in phenotype and genotype. Eur. J. Plant Pathol. 104:583-594.

13. Legard, D. E., Lee, T. Y., and Fry, W. E. 1995 Pathogenic specialization in Phytophthore infestans: aggressiveness on tomato. Phytopathology 85:1356-1361.

14. Ordoñez, M. E., Hohl, H. R., Velasco, A. Ramon, M. P., Oyarzun, P. J., Smart, C. D., Fry, W. E., Forbes, G. A., and Erselius, L. J. A novel A2 population of Phytophthora, similar to $P$. infestans, attacks wild Solanum species in Ecuador. Phytopathology. In press.

15. Oyarzun, P. J., Pozo, A., Ordonez, M. E., Doucett, K., and Forbes, G. A. 1998. Host specificity of Phytophthora infestans on tomato and potato in Ecuador. Phytopathology 88:265-271.

16. Spielman, L. J., Drenth, A., Davidse, L. C., Sujkowski, L. J., Gu, W., Tooley, P. W., and Fry, W. E. 1991. A second world-wide migration and population displacement of Phytophthora infestans? Plant Pathol. 40:422430.

17. Sujkowski, L. S., Goodwin, S. B., Dyer, A. T., and Fry, W. E. 1994. Increased genotypic diversity via migration and possible occurrence of sexual reproduction of Phytophthora infestans in Poland. Phytopathology 84:201-207. 